\title{
Supervisors, Construction and Extraction Workers
}

National Cancer Institute

\section{Source}

National Cancer Institute. Supervisors, Construction and Extraction Workers. NCI

Thesaurus. Code C122514.

Workers who directly supervise and coordinate activities of construction or extraction workers. 